\title{
EFFECT OF LEAN HOSPITAL ON WAITING TIME AT OUTPATIENT UNIT IN INDONESIA
}

\author{
Hairani, Agustin Kusumayati
}

Faculty of Public Health, Universitas Indonesia

\begin{abstract}
Background: Prolonged waiting time in hospitals especially in outpatient unit resulted in dissatisfaction among patients. In order to improve the efficiency, quality of healthcare, and patients' satisfaction, lean has been introduced widely as a quality improvement method at hospitals. It may improve patient flow to reduce the waiting time at the outpatient unit. This study aimed to review systematically the effect of lean hospital on waiting time at outpatient unit in Indonesia.

Subjects and Method: This was systematic review conducted by searching published articles from EBSCO, Science Direct, Google Scholar, and Willey Online Library. The key words were "waiting time", "waiting time improvement", "outpatient unit", and "lean hospital". The articles collected were using qualitative data. Initially 17,514 articles obtained. During screening 200 were excluded. After review process 4 articles were finally retained in this review.

Results: In outpatient unit, non-value added activity was higher ( $>70 \%)$ than value added activities $(<50 \%)$. Analysis of Cycle Time and Takt Time at outpatient unit showed that there were more work requests than it can process (Bottleneck). It causes interruption to the flow of work and delays the services. Waiting time was varying in all sectors including: (1) Registration (30.9 minutes); (2) Waiting for doctor (25.2 minutes); and (3) Submission of medical records (8.8 minutes). Implementation of lean hospital with eliminate non-value added and continuous improvement with Plan-Do-CheckAction (PDCA) cycle were efforts to reduce waiting time at outpatient unit in hospital

Conclusion: Lean hospital and continuous improvement at all levels are efforts to reduce waiting time at outpatient unit in hospital.
\end{abstract}

Keywords: waiting time, outpatient unit, Lean hospital.

\section{Correspondence:}

Hairani. Faculty of Public Health, Universitas Indonesia, Depok, West Java, Indonesia. Email: raniza22@yahoo.com. Mobile: 089507248144.

\section{BACKGROUND}

Quality health services are those that can satisfy every user of services that are in accordance with the average level of satisfaction of the population. Their implementation is also in line with established standards and professional codes of ethics. One way to provide good services for consumers can be realized if the hospital is able to manage the resources available in the hospital and maximize it (Graban 2009).

In many countries, prolonged waiting time is one of the factors that causes patients dissatisfaction with the hospital.

Hospital is a very complex organization, where it is known for its capital intens- ive, business intensive and labor intensive organizations. This situation requires hospital management to be able to maintain a balance between service quality and customer satisfaction. In addition, hospitals are required not only to be able to provide satisfactory services (customer satisfaction) but are also oriented to value (customer value). Organization does not merely pursue the achievement of high work productivity but also the performance that will be given (Gaspers and Fontana 2011).

Graban and Mark (2012) in the book Improving Quality, Patient Safety, and Employee Engagement said that Lean is a methodology that can be conducted by hospitals to 
improve the quality of service to patients by reducing error and waiting time. Lean is an approach that supports staff and medical personnel becoming more focused in providing services. It also helps in building more synergistic relationships inter-departments in hospitals.

Lean Management has been widely implemented in health care systems such as in America, Canada, and several European and other countries. However, the evidence-based information about its implementation in developing countries is still very limited.

Similar to Indonesia, the publication regarding the effect of implementing Lean, especially in hospital is still very limited. It provides an opportunity for health professionals, policy makers, researchers, and consultants to implement Lean in the context of each institution (Fraefel and Dörflinger, 2019).

Based on the Minimum Service Standard, waiting time for patients in polyclinic is defined as the duration of time when the patients start registering themselves until they meet with a doctor or specialist. Minister of Health Regulation number: 129/Menkes/SK/II/2008 concerning Minimum Service Standards in Outpatient Installation states that the ideal standard of waiting time for outpatients is $\leq 60$ minutes. Prolonged waiting time in the outpatient service process can inhibit the service. It also has an impact on the long queues, thus causing inefficient services.

Planned quality improvement and a clear flow of patients are essential for the optimization and efficiency of patient care. In the hospital operating system, the concept of Lean Hospital aims to eliminate waste and improve the service process. This study aimed to review the implementation of Lean hospital method to improve waiting time in outpatient services in hospitals.

\section{SUBJECTS AND METHOD}

\section{Study Design}

This was a systematic review conducted by searching published articles from EBSCO, Science Direct, Google Scholar, and Willey Online Library. The keywords were "waiting time", "waiting time improvement", "outpatient unit", and "Lean hospital”. The 17,514 articles were obtained. Data extraction was carried out using more specific categories with inclusion and exclusion criteria. Based on the search result, 200 articles were obtained.

\section{Inclusion and Exclusion Criteria}

The criteria for determining articles were based on the PRISMA method with inclusion and exclusion categories. The inclusion category was choosing review articles published in 2009-2019 with a qualitative study design, studying on improving waiting time with the output of Lean implementation in outpatient services at hospitals. The exclusion category was articles that had been published for more than 10 years

\section{Data Extraction}

Based on the inclusion and exclusion criteria, there were 23 articles that were in accordance with the abstract and the title. 4 out of 23 articles were selected to describe the implementation of Lean hospital in outpatient unit at hospital as a reference for further studies.

There were four main themes identified in the study. The first was he Implementation of Lean Management on Outpatient Services of BPJS Patient at Hermina Hospital, Depok, in 2017; This study aimed to improve efforts in the process flow in the outpatient installation. 

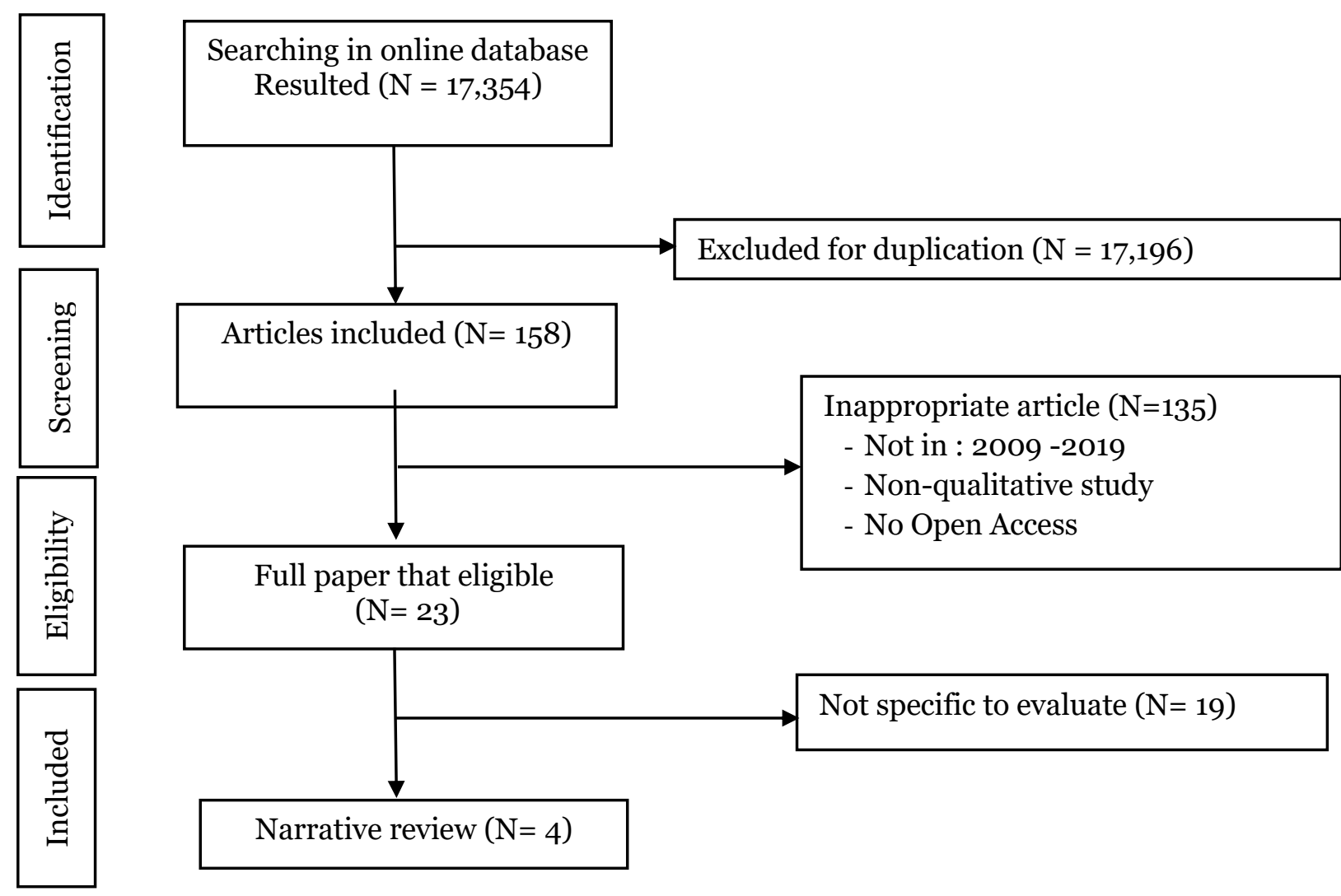

Figure 1. PRISMA Flow Diagram

Table 1. The Characteristic of the Article

\begin{tabular}{|c|c|c|c|c|c|}
\hline No & Title & $\begin{array}{l}\text { Author and } \\
\text { Years of } \\
\text { publication }\end{array}$ & Place & $\begin{array}{l}\text { Design of } \\
\text { the study }\end{array}$ & Variable \\
\hline 1 & $\begin{array}{l}\text { The Implementation } \\
\text { of Lean Managem- } \\
\text { ent on Outpatient } \\
\text { Services of BPJS } \\
\text { Patient at Hermina } \\
\text { Hospital, Depok, in } \\
2017\end{array}$ & $\begin{array}{l}\text { Noviani } \\
\text { (2017) }\end{array}$ & Indonesia & $\begin{array}{l}\text { Qualitati } \\
\text { ve Study }\end{array}$ & $\begin{array}{l}\text { The observation } \\
\text { and analysis with } \\
\text { value stream map- } \\
\text { ping and interview } \\
\text { methods to related } \\
\text { units }\end{array}$ \\
\hline 2 & $\begin{array}{l}\text { The Identification of } \\
\text { Waste on Patient Wait- } \\
\text { ing Time at Diponegoro } \\
\text { National Hospital using } \\
\text { the Lean Hospital } \\
\text { Approach }\end{array}$ & $\begin{array}{l}\text { Pualamsy } \\
\text { ah (2017) }\end{array}$ & Indonesia & $\begin{array}{l}\text { Qualitati } \\
\text { ve Study }\end{array}$ & $\begin{array}{l}\text { Analysis with curr- } \\
\text { ent state value str- } \\
\text { eam mapping (CS- } \\
\text { VSM), eliminating } \\
\text { waste, standardizi- } \\
\text { ng new processes } \\
\text { with future state } \\
\text { value stream map- } \\
\text { ping (FSVSM). }\end{array}$ \\
\hline 3 & $\begin{array}{l}\text { The Analysis of Outpat- } \\
\text { ient Services of Regio- } \\
\text { nal Public Hospitals in } \\
\text { Yogyakarta Using the } \\
\text { Lean Hospital }\end{array}$ & $\begin{array}{l}\text { Suryani } \\
\text { (2017) }\end{array}$ & Indonesia & $\begin{array}{l}\text { Qualitati } \\
\text { ve Study }\end{array}$ & $\begin{array}{l}\text { The result of the } \\
\text { observation was } \\
\text { made into Value } \\
\text { Stream Mapping to } \\
\text { identify the waste }\end{array}$ \\
\hline
\end{tabular}

The $6^{\text {th }}$ International Conference on Public Health Best Western Premier Hotel, Solo, Indonesia, October 23-24, 2019 | 365 https://doi.org/10.26911/the6thicph-FP.04.19 


\begin{tabular}{lll}
\hline Approach & & $\begin{array}{l}\text { and the location of } \\
\text { the bottleneck }\end{array}$ \\
\hline $\begin{array}{l}\text { Management of Impro- } \\
\text { vement of Patient Wait- } \\
\text { ing Time by Using the } \\
\text { Concept of Lean Hospi- } \\
\text { tal in an Effort to Impr- } \\
\text { ove the Quality of Wait- } \\
\text { ing Time at Santo Bor- } \\
\text { romeus Hospital in } \\
\text { Bandung }\end{array}$ & $\begin{array}{l}\text { Observation and } \\
\text { in-depth intervi- } \\
\text { ews with related } \\
\text { units and patients }\end{array}$ \\
\end{tabular}

The second theme was The Identification of Waste on Patient Waiting Time at Diponegoro National Hospital using the Lean Hospital Approach. This study aimed to identify the waste that occurred in the internal medicine clinic. The third theme was The Analysis of Outpatient Services of Regional Public Hospitals in Yogyakarta Using the Lean Hospital Approach. This study aimed to identify the flow of outpatient services, identify waste, the location of the bottleneck, and provide suggestions for improvement with the Lean Hospital approach. The last theme was The Management of Improvement of Patient Waiting Time by Using the Concept of Lean Hospital.

In improving the quality of waiting time, this study used a survey of waiting time of patients from the outpatient and emergency department who would be treated and patients who recovered from inpatient care at Santo Borromeus Hospital Bandung.

\section{RESULTS}

The process of implementing Lean hospital in this study referred to 5 established Lean principles. Here are 5 principles from Lean thinking (McManus, 2012; Graban, 2012; Joosten, 2009; Nave, 2002), namely:

1. Identification of value, based on the patient's perspective

2. Identification of value stream map, all value added steps were described by con- necting one part to another (value stream), eliminating steps that did not produce value

3. Plot improvement, eliminating the cause of delay

4. Pull value, avoiding forced labor to next process or department; letting an activity and supplies be pulled as needed

5. Pursue perfection, continuous process improvement.

The implementation of Lean hospital as an effort to improve waiting time in hospitals was adjusted to the Lean principle, such as:

1. Eliminating waste, increasing operational efficiency and response time

2. Finding problems that were or would occur quickly, and making improvements on an ongoing basis

3. Creating a consistent and stable environment.

The implementation of Lean hospital that was used by the researchers in an effort to improve waiting time in hospitals in Indonesia began with observing with Value Stream Mapping to identify the waste and the location of the bottleneck. The next step was to eliminate waste and find the main cause of the problem using the Fishbone Diagram and proposed improvements to be implemented in hospitals by examining the inhibiting factors ranging from man, machine, method, material and environment. 
Based on the result of identification with Value Stream Mapping, the average of value added in hospital outpatient units was $<50 \%$ and non-value added was $>70 \%$. There was still waste in non-value added activity. Waste that occurred was waste of defect, transportation, motion, waiting, overproduction, over processing, inventory, and waste of talent/human potential. Based on the analysis of cycle time and takt time, bottlenecks occurred at the Polyclinic. The longest activity of the waiting time process at the polyclinic was waiting at the registration window (30.9 minutes), the second was queuing to meet a specialist doctor (25.2 minutes), and the third was delivering medical record to the nurse (8.8 minutes).

In each process, there were inter actions occurred between elements of man, machine, method, material, and environment. Based on the Fishbone Diagram, the main causes of the problem of waiting time were from the elements of Man: doctors arrived late, bad work culture, the Standard Operating Procedures were not implemented, and Lean hospital was not evenly understood, Machine: Integrated IT was not optimal, the storage of medical record documents was in the several places, computerized medical record input was $>2$ minutes, and there was no electronic prescription, Method: the Standard Operating Procedures have not been run consistently, the writing of prescription drugs did not use capital letters, Material: the information regarding service product did not evenly distributed, increasing number of insurance/National Health Insurance patients, Environment: the location of each room was far apart.

Based on the finding of this study, there were activities that cause non-value added or waste in each process in the VSM diagram. The activities that caused or were identified as waste were proposed to be improved in 3 stages, namely short term, medium term and long term.

One of the improvements made by the concept of Lean hospital included $5 \mathrm{~S}$, inventory, and visual management. The results of the intervention were a decrease in the percentage of non-value added activities from $90 \%$ to $78.30 \%$ and an increase in value added activities from $10 \%$ to $21.70 \%$.

In the organization, there were several methodological theories used in the improvement process. The methodology could be adapted to the situation and condition that occurred in the organization (Nave, 2002).

\section{DISCUSSION}

In the last few decades, there were hospitals throughout the world have tried to adopt the Lean management system. It aimed to increase the efficiency and effectiveness of their operations. In Indonesia, the implementation of Lean Management increased with the implementation of the National Health Insurance $(\mathrm{JKN})$ system since January 1, 2014.

Lean Hospital is one of the current approaches to improve efficiency and quality services. Lean is a way for hospitals to improve the efficiency and quality of their services by empowering staff. This is a method for involving doctors, nurses, and hospital staff to manage their work. Therefore, it can improve the process and provide better and faster services with lower costs.

The implementation of Lean hospital is similar with Lean manufacturing which used Lean tools as a tool to identify and solve a problem. The Lean tools commonly used are Value Stream Mapping, $5 \mathrm{~S}$, Visual Management, A3 Report, and Kaizen. The purpose of implementing Lean hospital is to identify something that had non-value added and maintain and enhance activities that have value added in line with customer request, 
such as patient, with the goal of customer satisfaction.

In order to implement the Lean concept in hospital, a manager needs to understand what types of "waste" in the hospital. In addition, a manager should be able to identify the waste produced in the hospital. The seven types of waste are:

1. Overproduction, for example filling out forms repeatedly, repetitive information in various documents, repetitive and ineffective social service cycles, and so on

2. Waste of time, for example the core team is waiting for the support team, patients are waiting for a follow-up meeting with the doctor, waiting for a room in the ward, and so on.

3. Waste in transportation, for example the core team moves from one floor to another floor to visit patients, waiting for transportation to move patients from the ward to the diagnostic room or to the operating room, and so on.

4. Waste in the production process, for example, multiple layers that must be filled in with patient information, conducting more supporting check up than recommended, re-examines, and so on.

5. Waste in the inventory, for example, the supply of certain types of drugs which far exceeds the needs, unnecessary instruments which are in the instrument box in OK, unclear graphics, files, documents, or working papers that are not quite useful

6. Waste of movement, for example, nurses leave the ward to look for general needs (office stationeries or certain drugs), look for patients, look for documents, and so on.

7. Waste as a result of failed products, for example complication and medical error. A hospital manager also needs to understand the value desired by the customer, namely good, safe, efficient and appropriate service quality. In this case, there are external customers (patients, patients' families, payers, regulators) and internal customers (doctors, nurses and other staff).

The implementation of Lean can give a significant effect on the operational efficiency and effectiveness. The effects of implementing Lean at the hospital, include: 1) Patient O $\backslash$ outcome: patient satisfaction, 2) Outcome of the provider: staff satisfaction, 3) Access and utilization: length of stay (LOS), waiting time, 4) Danger/amost Injured: figures of errors related to patient safety, 5) Resource use: costs, cycle time, error rates related to resources (Rotter et al., 2017).

In this study, the implementation of Lean Hospital has been carried out in accordance with the specified stages. In addition, the effect of the implementation of Lean hospital in improving outpatient waiting time was increasing the flow to be more efficient. It is expected to increase patient productivity and satisfaction. However, the improvement effort must involve continuous improvement. It involves all levels of employees, so that the implementation of Lean Hospital can reach the results that were in accordance with the goals.

The implementation of Lean hospitals requires several considerations that must be considered by hospital stakeholders in order to achieve the real goal of implementing Lean hospital, namely:

1. Human resources

Human resources must have a mindset of continuous improvement with problem solving and kaizen mindset. In order to get employees like this, the hospital should provide training related to the stages and steps in solving problems. Therefore, the understanding of the problem and how to solve it will be more directed. 
2. The participation of all parties from all levels of position

Every level of employees must participate in improving the quality of service and hospital operations.

3. Communication skills

The ability to communicate is a main factor in inviting all parties to contribute to the continuous improvement without any coercion from any party.

\begin{tabular}{c}
\hline REFERENCES \\
\hline Depkes RI (2008). Menteri Kesehatan Repu- \\
blik Indonesia Nomor: 129/Menk- \\
es/SK/II/2008, Tentang Standar Pe- \\
layanan Medis. Departemen Keseh- \\
atan RI.
\end{tabular}

Fraefel M, Dörflinger M (2019) Lean Hospital Management. Retrieved from https://implementconsultinggroup.co $\mathrm{m} /$ Lean-hospital-management/.

Graban M (2011) Lean Hospitals: Improving Quality, Patient Safety, and Employee Engagement, Second Edition. CRC Press.

Ishijima H, Eliakimu E, Mshana JM (2016). The " $5 \mathrm{~S}$ " approach to improve a working environment can reduce waiting time: Findings from hospitals in Northern Tanzania. The TQM Journal 28(4).

Laureani A, Antony J (2019). Leadership and Lean Six Sigma. A systematic literature review. Total Qual Manag Bus Excell.
Lawal AK, Rotter T, Kinsman L, Sari N, Harrison L, Jeffery C, Kutz M, Khan MF, Flynn R (2014). Lean management in health care: definition, concepts, methodology and effects reported (systematic review protocol). Doi: 10.1186/2046-4053-3-103

Marco CA, Moskop JC, Schears RM, Stankus JL, Bookman KJ, Padela AI, Baine J, Bryant E (2012). The Ethics of Health Care Reform: Impact on Emergency Medicine. Academic Emergency Medicine, 19(4).

Rotter T, Plishka CT, Adegboyega L (2017). Lean management in health care: Effects on patient outcomes, professional practice, and healthcare systems. Cochrane Database Syst Rev.

Rotter T, Plishka C, Lawal A, Harrison L, Sari N, Goodridge D, Flynn R, Chan J, Fiander M, Poksinska B, Willoughby $\mathrm{K}$, Kinsman L (2018). What Is Lean Management in Health Care? Development of an Operational Definition for a Cochrane Systematic Review.

Terra JDR, Berssaneti FT. (2018) Application of Lean healthcare in hospital services: A review of the literature (2007 to 2017).

Varela L, Araújo A, Ávila P, Castro H, Putnik $G$ (2019). Evaluation of the relation between Lean manufacturing, industry 4.0, and sustainability 